\title{
Berberine ameliorates the LPS-induced imbalance of osteogenic and adipogenic differentiation in rat bone marrow-derived mesenchymal stem cells
}

\author{
RONG ZHOU* , FUBO CHEN*, HAIXIA LIU, XUEQIN ZHU, XUEYUN WEN, \\ FANG YU, GUANGWEI SHANG, SHENGCAI QI and YUANZHI XU \\ Department of Stomatology, Shanghai Tenth People's Hospital, \\ Tongji University School of Medicine, Shanghai 200072, P.R. China
}

Received July 30, 2020; Accepted February 25, 2021

DOI: $10.3892 / \mathrm{mmr} .2021 .11989$

\begin{abstract}
Lipopolysaccharide (LPS) from oral pathogenic bacteria is an important factor leading to alveolar bone absorption and the implant failure. The present study aimed to evaluate the modulation of berberine hydrochloride (BBR) on the LPS-mediated osteogenesis and adipogenesis imbalance in rat bone marrow-derived mesenchymal stem cells (BMSCs). Cell viability, osteoblastic and adipogenic differentiation levels were measured using the Cell Counting Kit- 8 assay, alkaline phosphatase (ALP) staining and content assay, and oil red O staining, respectively. Reverse transcription-quantitative PCR and immunoblotting were used to detect the related gene and protein expression levels. In undifferentiated cells, BBR increased the mRNA expression levels of the osteoblastic genes (Alp, RUNX family transcription factor 2, osteocalcin and secreted phosphoprotein 1) but not the adipogenic genes (fatty acid binding protein 4, Adipsin and peroxisome proliferator-activated receptor $\gamma$ ). LPS-induced osteoblastic gene downregulation, adipogenic gene enhancement and NF- $\mathrm{B}$ activation were reversed by BBR treatment. In osteoblastic differentiated cells, decreased ALP production by LPS treatment was recovered with BBR co-incubation. In adipogenic differentiated cells, LPS-mediated lipid accumulation was decreased by BBR administration. The mRNA expression levels of the pro-inflammatory factors (MCP-1, TNF- $\alpha$, IL-6 and IL-1 $\beta$ ) were increased by LPS under both adipogenic and
\end{abstract}

Correspondence to: Professor Yuanzhi Xu or Dr Shengcai Qi, Department of Stomatology, Shanghai Tenth People's Hospital, Tongji University School of Medicine, 301 Yanchang Road, Shanghai 200072, P.R. China

E-mail: amyxyz01@hotmail.com

E-mail: dentistqi@163.com

*Contributed equally

Key words: berberine, bone marrow-derived mesenchymal stem cells, osteogenesis, adipogenesis, lipopolysaccharide osteoblastic conditions, which were effectively ameliorated by BBR. The actions of BBR were attenuated by compound $\mathrm{C}$, suggesting that the role of BBR may be partly due to AMP-activated protein kinase activation. The results demonstrated notable pro-osteogenic and anti-adipogenic actions of BBR in a LPS-stimulated inflammatory environment. This indicated a potential role of BBR for bacterial infected-related peri-implantitis medication.

\section{Introduction}

To improve the quality of life in patients with dentition defects and delay the absorption of the alveolar bone, osteointegrated dental implants have been developed and have been widely used since the 1980s $(1,2)$. With the popularization of the dental implant, inflammation in the mucosa and bone tissues around the implant has become a new problem (3). The formation of the bacterial biofilm, on the surface of the implant and in the peripheral gingival crevicular fluid, stimulates the inflammatory reaction and finally leads to alveolar bone absorption. In serious cases, the implant has been found to loosen and fall off $(3,4)$. A meta-analysis based on 15 articles of 11 studies during 2006 to 2014, found that the incidence of peri-implantitis was $22 \%(5,6)$. At present, the primary clinical treatment aim of peri-implantitis is to control the pathogens and reduce the periodontal pockets around the implant, using subgingival curettage, antibiotics and laser treatment $(7,8)$. However, it is difficult to reverse the process of bone absorption. Therefore, it is important to identify a drug or material that can inhibit the pathogenic bacteria-induced inflammation and improve the bone regeneration capability.

Several of the major pathogens of peri-implantitis belong to Gram-negative bacterium, which produce lipopolysaccharide (LPS) in their cell wall (9). LPS predominantly activates the Toll-like receptor 4 (TLR4)/NF- $\kappa \mathrm{B}$ signaling pathway and induces pro-inflammatory cytokine expression, including TNF- $\alpha$, IL- 6 , IL-1 $\beta$ and monocyte chemoattractant protein-1 (MCP-1) (10). Enhancement of LPS-induced receptor activator of $N F-\kappa B$ ligand (RANKL) and autophage activation was found to promote osteoclastogenesis $(11,12)$. Furthermore, LPS could adhere to the surface of the titanium implant, 
which had no effect on cell attachment but impaired osteoblast differentiation (13). Therefore, LPS is a contributing factor in both soft-tissue destruction and alveolar bone absorption, affecting the implant success rate (14).

As a key factor during the development of peri-implantitis, the balance of alveolar bone absorption and reconstruction was found to be damaged (15). Alveolar bone regeneration includes two aspects: The osteoclastogenesis of monocyte macrophages and the osteogenesis of mesenchymal stem cells (15). Bone marrow-derived mesenchymal stem cells (BMSCs) are a type of multipotent cell, which are considered to be common progenitors for osteoblasts and adipocytes (16). BMSCs have been applied for bone repair, due to their osteogenic ability (17). Thus, in the current study, BMSCs were used to investigate the regulation of osteogenesis. As aforementioned, LPS was found to impair osteoblast differentiation; in addition, a previous study has reported that LPS could affect the potential differentiation tendency of BMSCs (18). Therefore, it is important to investigate the regulation of drugs on LPS-induced osteogenesis/adipogenesis imbalance and inflammation in BMSCs.

Berberine is a type of quaternary ammonium alkaloid, extracted from varieties of plants species, such as Coptis chinensis (19). Berberine hydrochloride (BBR) is typically used in a clinical setting, due to its numerous pharmacological activities, including anti-microbial, glucose/ cholesterol regulatory and immune modulatory properties (19). Previous studies have revealed that it is implicated in bone biology. For instance, BBR inhibited adipogenesis and promoted osteogenesis in the C3H10T1/2 cell line (20). In addition, berberine suppressed RANKL-induced osteoclast formation and protected cell survival $(21,22)$. However, the role of BBR on osteogenesis and adipogenesis under inflammatory conditions remains unknown. The aim of the present study was to demonstrate the modulating effect of BBR on the osteogenesis/adipogenesis balance in LPS-mediated inflammatory response in BMSCs, which may provide novel evidence for peri-implantitis medication.

\section{Materials and methods}

Materials. BBR, LPS (extracted from Escherichia coli O111:B4 strain), L-ascorbic acid, $\beta$-glycerophosphate disodium, dexamethasone (Dex), 3-isobutyl-1-methylxanthine (IBMX) and indomethacin were purchased from Sigma-Aldrich (Merck $\mathrm{KGaA}$ ). Compound $\mathrm{C}$ was obtained from CSNpharm, Inc. The Cell Counting Kit (CCK)-8 was purchased from Dojindo Molecular Technologies, Inc. The alkaline phosphatase (ALP) content assay kit, the ALP stain kit, BeyoECL Moon (ECL chemiluminescence kit), protease inhibitor cocktail, phosphatase inhibitor cocktail and insulin were purchased from Beyotime Institute of Biotechnology. The oil Red O Stain kit was purchased from Cyagen Biosciences, Inc., and the PrimeScript $^{\mathrm{TM}}$ RT kits was obtained from Takara Bio, Inc. The Kapa SYBR ${ }^{\circledR}$ Fast QPCR Master Mix (2X) Universal kit was purchased from Roche Diagnostics and the primers were synthesized by Sangon Biotech Co., Ltd. The RIPA lysis buffer and TRIzol ${ }^{\circledR}$ reagent were purchased from Thermo Fisher Scientific, Inc., while the antibodies against phosphorylated (p)-p65 (cat. no. 3033), total p65 (cat. no. 8242), (p)-ІкB $\alpha$ (cat. no. 2859), total IкB $\alpha$ (cat. no. 9243) and anti-rabbit
IgG HRP-linked (cat. no. 7074) were purchased from Cell Signaling Technology, Inc. The anti-GAPDH antibody (cat. no. 10494-1-AP) was purchased from ProteinTech Group, Inc. Basic $\alpha$-modified Eagle medium ( $\alpha$-MEM), FBS and penicillin-streptomycin antibiotics were purchased from Thermo Fisher Scientific, Inc. Other reagents were of analytical grade and used without further purification.

Primary cell isolation and culture. Female Sprague-Dawley rats (age, 3 weeks; weight, 80-100 g; 20-26 ; relative humidity 40-70\%; 12-h light/dark cycle; diet and drinking water ad libitum) were sacrificed using carbon dioxide (2 1/min in a 10-1 box). The femur and tibia of the rats were isolated and the bone marrow cavity was washed with $\alpha$-MEM to obtain the primary BMSCs. The cells were collected and centrifuged at $1,000 \mathrm{x} \mathrm{g}$ for $10 \mathrm{~min}$ at room temperature. After removing the supernatant, the aspirates were re-suspended with BMSC growth medium ( $\alpha$-MEM containing 10\% FBS, $100 \mathrm{U} / \mathrm{ml}$ penicillin and $100 \mathrm{mg} / \mathrm{ml}$ streptomycin) and seeded in a $10-\mathrm{cm}$ dish for 3 days at $37^{\circ} \mathrm{C}$, and then the non-adherent cells were removed. Adherent BMSCs were further cultured and expanded. Cells that passaged 3-6 times were used for further experimentation.

Cell viability assay. The BMSCs cells were seeded into 96-well plates $(5,000$ cells per well) and cultured overnight, then treated with BBR at different concentrations $(0,1,5,10,50$ and $100 \mu \mathrm{M})$ at $37^{\circ} \mathrm{C}$ for $72 \mathrm{~h}$. Cell viability was measured using the CCK-8 kit according to the manufacturer's protocol. After removing the supernatant, fresh growth medium containing CCK-8 (Vcck-8:Vmedium, 1:10) was added into each well and incubated at $37^{\circ} \mathrm{C}$ for $2 \mathrm{~h}$. The absorbance of the samples was measured at $450 \mathrm{~nm}$ using a Synergy 2 microplate reader (Agilent Technologies, Inc.).

$R N A$ isolation and reverse transcription-quantitative (RT-q) $P C R$ analysis. Total RNA was extracted using TRIzol ${ }^{\circledR}$, and subsequently isolated with isopropanol and chloroform according to the manufacturer's protocol. RT reactions and qPCR detections were performed according to the manufacturer's instructions. The reverse transcription reaction was: $37^{\circ} \mathrm{C}$ for $15 \mathrm{~min}, 85^{\circ} \mathrm{C}$ for $15 \mathrm{sec}$. The program of the qPCR thermocycling was: First step: $95^{\circ} \mathrm{C}$ for $3 \mathrm{~min}$; second: $95^{\circ} \mathrm{C}$ for $3 \mathrm{sec}$ and $60^{\circ} \mathrm{C}$ for $30 \mathrm{sec}$, repeated for 40 cycles. The reactions were performed using Eppendorf Mastercycler Pro and an ABI 7900 Real-time PCR system (Thermo Fisher Scientific, Inc.). The relative mRNA expression levels were normalized to GAPDH using the comparative $2^{-\Delta \Delta \mathrm{Cq}}$ method (23). The PCR primer pairs are shown in Table I.

Western blot analysis. BMSCs were lysed with RIPA lysis buffer containing protease inhibitor cocktail and phosphatase inhibitor cocktail. Cell lysate was collected, and its total protein concentration was determined using a BCA kit (Thermo Fisher Scientific, Inc.). Total protein $(\sim 20 \mu \mathrm{g})$ was loaded in each lane and separated using SDS-PAGE (12.5\%) and then transferred onto PVDF membranes. The membranes were blocked by $5 \%$ non-fat milk in PBST buffer (PBS containing 0.1\% Tween-20) for $1 \mathrm{~h}$ at room temperature. Then the membranes were incubated with the corresponding primary antibodies (the

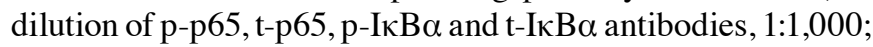


Table I. Primer sequences for reverse transcription-quantitative PCR.

\begin{tabular}{|c|c|c|}
\hline Gene & Forward primer sequence $\left(5^{\prime}-3^{\prime}\right)$ & Reverse primer sequence $\left(5^{\prime}-3^{\prime}\right)$ \\
\hline$A L P$ & AACGTGGCCAAGAACATCATCA & TGTCCATCTCCAGCCGTGTC \\
\hline$R U N X 2$ & GCACCCAGCCCATAATAGA & TTGGAGCAAGGAGAACCC \\
\hline$O C N$ & TGAGGACCCTCTCTCTGCTC & GGGCTCCAAGTCCATTGTT \\
\hline$S P P 1$ & ATCTGAGTCCTTCACTG & GGGATACTGTTCATCAGAAA \\
\hline$F A B P 4$ & GCGTAGAAGGGGACTTGGTC & TTCCTGTCATCTGGGGTGATT \\
\hline$A D I P S I N$ & CACGTGTGCGGTGGCACCCTG & СCCCTGCAAGTGTCCCTGCGGT \\
\hline$P P A R \gamma$ & CCTTTACCACGGTTGATTTCTC & GGCTCTACTTTGATCGCACTTT \\
\hline$M C P-1$ & TGCTGTCTCAGCCAGATGCAGTTA & AGAAGTGCTTGAGGTGGTTGTGGA \\
\hline$T N F-\alpha$ & CCCAATCTGTGTCCTTCTAACT & CAGCGTCTCGTGTGTTTCT \\
\hline Il-6 & GGTTTGCCGAGTAGACCTCA & GTGGCTAAGGACCAAGACCA \\
\hline$I l-1 \beta$ & AAAGAAGGTGCTTGGGTCCT & CAGGAAGGCAGTGTCACTCA \\
\hline$G A P D H$ & CAGGGCTGCCTTCTCTTGT & TCCCGTTGATGACCAGCTTC \\
\hline
\end{tabular}

ALP, alkaline phosphatase; Runx2, RUNX family transcription factor 2; Ocn, osteocalcin; Spp1, secreted phosphoprotein 1; Fabp4, fatty acid binding protein 4; Ppar $\gamma$, peroxisome proliferator-activated receptor $\gamma$; MCP-1, monocyte chemoattractant protein-1.

GAPDH antibody, 1:5,000) at $4^{\circ} \mathrm{C}$ overnight. The membranes were washed 3 times with PBST buffer, 10 min each time, and then incubated with HRP-linked anti-Rabbit $\operatorname{IgG}(1: 2,000)$ for $2 \mathrm{~h}$ at room temperature. The membranes were then washed 3 times, as previously. An ECL chemiluminescence kit (cat. no. P0018FS; Beyotime Institute of Biotechnology) was used for HRP detection. GE Amersham Imager 600 (Cytiva) was used for signal collection. Semi-quantification of band intensity was performed using ImageJ v1.44p software (National Institute of Health). Data are presented as the mean \pm SD from three independent experiments.

Osteogenic and adipogenic differentiation. BMSCs were seeded into 12 -well plates at a density of $2 \times 10^{4}$ cells $/ \mathrm{cm}^{2}$ and cultured until confluent. To identify the effects of drug administration, LPS $(1 \mu \mathrm{g} / \mathrm{ml}), \operatorname{BBR}(1,5$ and $10 \mu \mathrm{M})$ and compound $\mathrm{C}(1 \mu \mathrm{M})$ were used, unless otherwise specified. For osteogenic differentiation, $10 \mathrm{nM}$ Dex, $100 \mathrm{mg} / \mathrm{l}$ L-ascorbic acid and $10 \mathrm{mM} \beta$-glycerophosphate disodium were added to the BMSC growth media, co-incubated with given drug simultaneously. The osteoblastic media with drugs was replaced every 3 days. On day 7, the cells were harvested for ALP staining, intracellular ALP content assay and gene expression level analysis. For adipogenic differentiation, $1 \mu \mathrm{M}$ Dex, $0.5 \mathrm{mM}$ IBMX, $10 \mu \mathrm{g} / \mathrm{ml}$ insulin and $100 \mu \mathrm{M}$ indomethacin were added to the BMSC growth media. The cells were incubated with the adipogenic media and corresponding drugs at $37^{\circ} \mathrm{C}$ for 12 days, and the media was replaced every 3 days. Then, the cells were harvested for oil red $\mathrm{O}$ staining.

ALP stain and intracellular content assay. Following treatment with osteogenic media and corresponding drugs for 7 days, the BMSCs were washed with PBS and fixed with $4 \%$ paraformaldehyde for $30 \mathrm{~min}$ at room temperature. Following which, the cells were washed three times with PBS to remove the fixing liquid. The ALP staining solution was mixed according to the manufacturer's instructions, and added to the wells of the culture plate. After 30 -min incubation at room temperature, the cells were washed with sterile water three times and images were obtained using a light microscope at x200 magnification (Leica Microsystems GmbH).

For the ALP content assay, cells were treated as aforementioned, then washed with PBS and collected using a lysis buffer. The concentration of the samples was detected using a BCA kit (Thermo Fisher Scientific, Inc.). Each sample was diluted to $2 \mathrm{mg} / \mathrm{ml}$, and the ALP content was measured according to the manufacturer's instructions. The absorbance was measured at $405 \mathrm{~nm}$.

Oil red $O$ stain. The oil red $\mathrm{O}$ working solution was prepared by diluting the stock solution with sterile water (Vstock:Vwater, 3:2). After differentiation for 12 days, the BMSCs were washed with PBS, fixed with $4 \%$ formaldehyde at room temperature for $15 \mathrm{~min}$ and then stained with freshly diluted oil red $\mathrm{O}$ working solution for $60 \mathrm{~min}$ at room temperature. Following which, the supernatant was removed and the cells were washed with water three times. Images of the oil red O-positive cells were collected using a bright-field microscope at $\mathrm{x} 200$ magnification.

Statistical analysis. Data are presented as the mean \pm SD from three separate experiments in each group. Statistical differences between groups were analyzed using one-way ANOVA, multiple comparisons between the groups were performed using Tukey's test with GraphPad Prism version 6 (GraphPad Software, Inc.). $\mathrm{P}<0.05$ was considered to indicate a statistically significant difference.

\section{Results}

$B B R$ reverses the LPS-induced decrease in osteogenic gene expression and increase in adipogenic gene expression levels. Firstly, to investigate the potential cytotoxicity of BBR, BMSCs were treated with different concentrations of BBR 
A

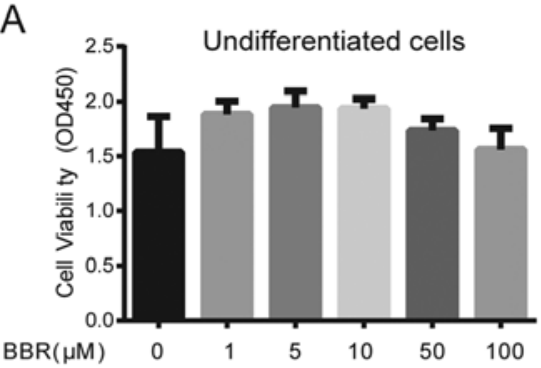

B

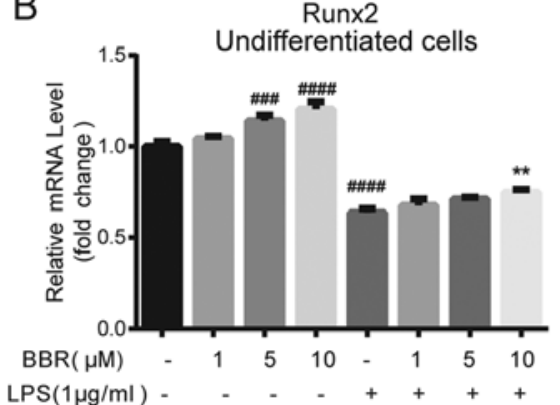

E

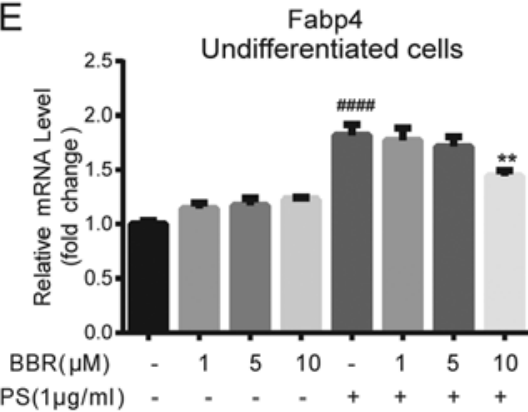

C

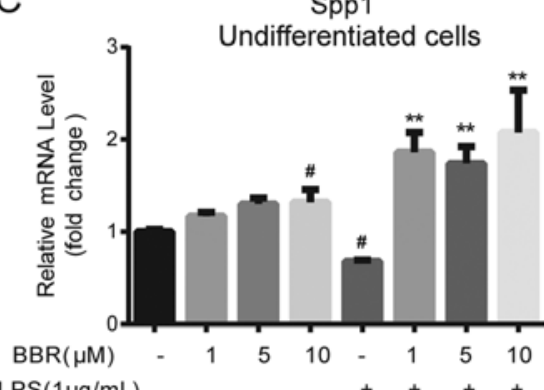

F

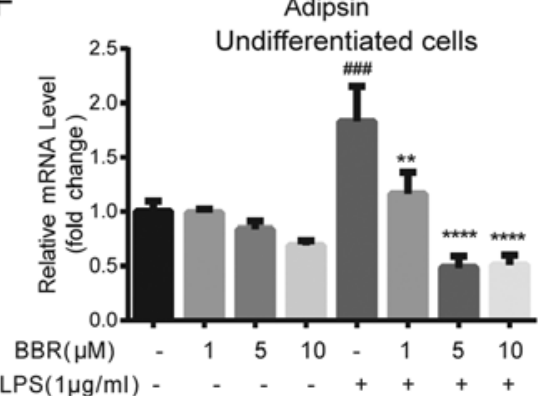

D

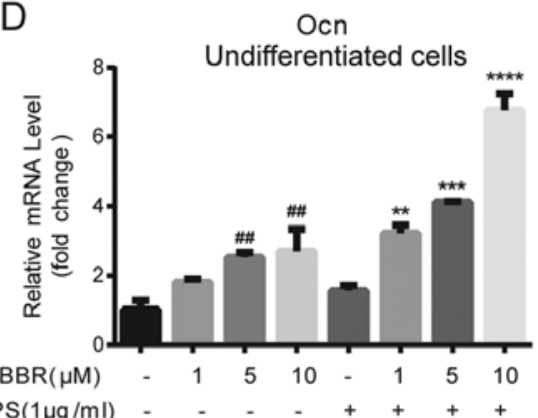

G

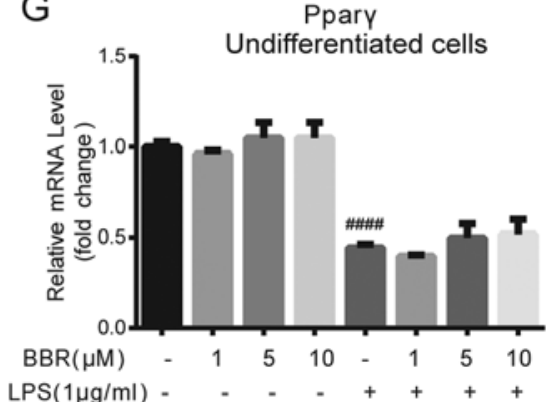

Figure 1. BBR alters osteogenic and adipogenic gene expression levels in undifferentiated bone marrow-derived mesenchymal stem cells. (A) Cells were incubated with DMSO or BBR $(1,5,10,50$ or $100 \mu \mathrm{M})$ for 3 days, and then cell viability was determined using a Cell Counting Kit- 8 assay. The cells were treated with BBR $(1,5$ or $10 \mu \mathrm{M})$ alone or simultaneously with LPS $(1 \mu \mathrm{g} / \mathrm{ml})$, and then collected for reverse transcription-quantitative PCR analysis. The mRNA expression levels of the osteogenic genes (B) Runx2, (C) Spp1 and (D) Ocn, and the adipogenic genes (E) Fabp4, (F) Adipsin and (G) Ppar $\gamma$ were measured. Their relative changes were normalized to the GAPDH expression levels. The data are presented as the mean \pm standard deviation of three independent experiments. ${ }^{\#} \mathrm{P}<0.05,{ }^{\# \#} \mathrm{P}<0.01,{ }^{\# \# \#} \mathrm{P}<0.001,{ }^{\# \# \# "} \mathrm{P}<0.0001$ vs. control group; ${ }^{* *} \mathrm{P}<0.01,{ }^{* * *} \mathrm{P}<0.001,{ }^{* * * * *} \mathrm{P}<0.0001$ vs. LPS group. BBR, berberine hydrochloride; LPS, lipopolysaccharide; Runx2, RUNX family transcription factor 2; Ocn, osteocalcin; Spp1, secreted phosphoprotein 1; Fabp4, fatty acid binding protein 4; Ppar $\gamma$, peroxisome proliferator-activated receptor $\gamma$.

for 3 days and the cell viability was measured. As shown in Fig. 1A, BBR had no significant cytotoxic effect on BMSCs; therefore low concentrations, at $1-10 \mu \mathrm{M}$ were selected for subsequent experiments. Additionally, the cytotoxic effects of LPS at different concentrations were also detected. At the dose of $1 \mu \mathrm{g} / \mathrm{ml}$, LPS had no significant cytotoxic effect; however, $10 \mu \mathrm{g} / \mathrm{ml}$ LPS exhibited weak cytotoxicity (data not shown).

As LPS-related adverse effects on bone reconstruction are a key factor in the development of peri-implantitis (14), the potential role of BBR on osteogenic and adipogenic gene expression in undifferentiated BMSCs was investigated. The cells were co-incubated with BBR at different concentrations $(0,1,5$ and $10 \mu \mathrm{M})$ and with or without $1 \mu \mathrm{g} / \mathrm{ml}$ LPS for 3 days . The results demonstrated that BBR significantly promoted the mRNA expression levels of osteogenic genes, RUNX family transcription factor 2 (Runx2), osteocalcin (Ocn) and secreted phosphoprotein 1 (Sppl), in a dose-dependent manner (Fig. 1B-D). Notably, LPS significantly decreased the Runx2 and SPP1 mRNA expression levels, and these effects were partly or totally reversed by BBR. The Ocn mRNA expression level was not changed by LPS; however, it was increased after BBR treatment under the LPS-stimulated condition. For the adipogenic genes, compared with the negative control, LPS induced a two-fold increase in both fatty acid binding protein 4 (Fabp4) and Adipsin gene expression levels (Fig. 1E and $\mathrm{F}$ ); however, the peroxisome proliferator-activated receptor $\gamma$ (Ppar $\gamma$ ) expression level decreased by half (Fig. 1G). BBR itself had little effect on the adipogenic genes, except for Adipsin, and a small reduction in the increase of Fabp4 expression levels induced by LPS. Moreover, $10 \mu \mathrm{M}$ BBR lowered Adipsin gene expression level, and further dose-dependently reduced the increase stimulated by LPS.

BBR promotes BMSC osteogenic differentiation under LPS treatment. As aforementioned, it was determined that BBR could ameliorate the LPS-induced inhibition of BMSCs osteogenic gene expression. Considering that ALP is a key protein during the differentiated process, particularly in the early and 
A

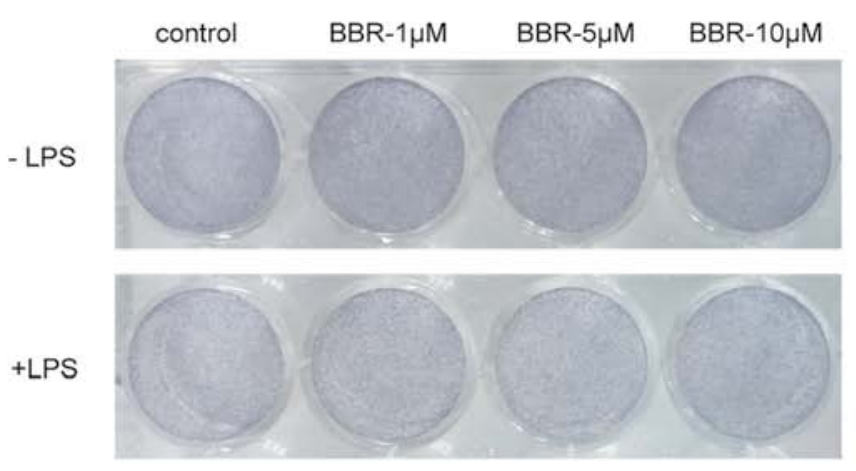

C

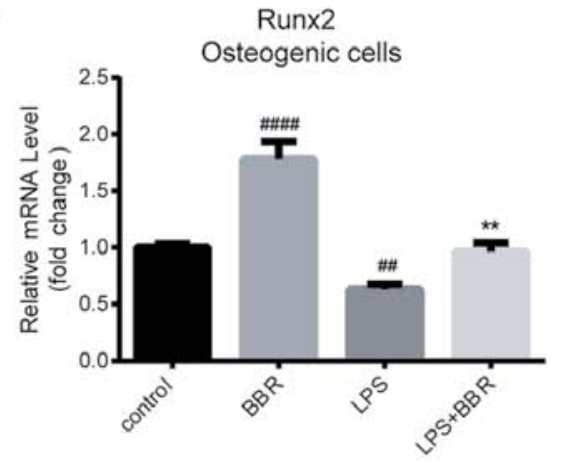

D

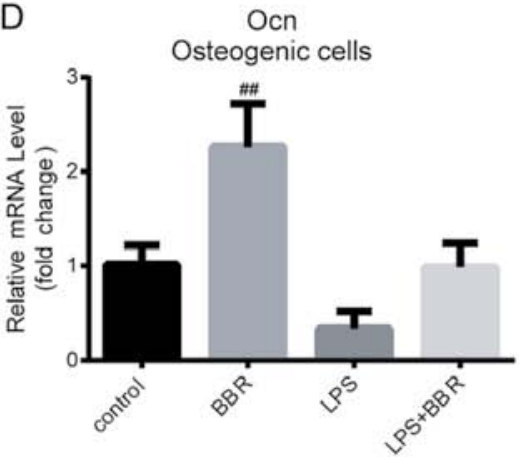

B
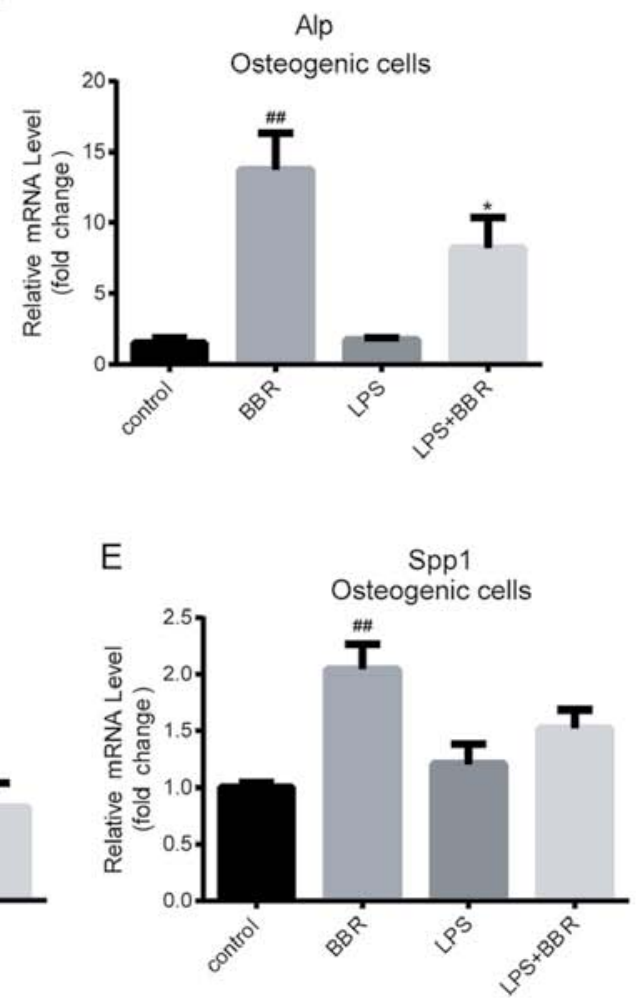

Figure 2. BBR promotes osteogenesis in bone marrow-derived mesenchymal stem cells. The cells were incubated with BBR ( 0 , 1,5 or $10 \mu \mathrm{M})$ alone or simultaneously with LPS $(1 \mu \mathrm{g} / \mathrm{ml})$ in osteogenic media for 7 days. Then, the cells were detected using ALP stain and reverse transcription-quantitative PCR analysis. (A) Images of the ALP stained cells were obtained using a camera. The mRNA expression levels of the (B) Alp, (C) Runx2, (D) Ocn and (E) Spp1 osteogenic genes were measured. Their relative changes were normalized to the GAPDH expression levels. The data are presented as the mean \pm standard

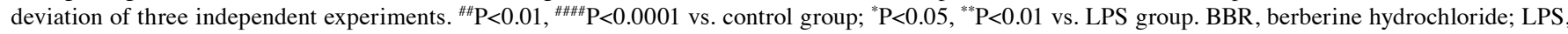
lipopolysaccharide; Runx2, RUNX family transcription factor 2; Ocn, osteocalcin; Spp1, secreted phosphoprotein 1; ALP, alkaline phosphatase.

middle stages (24), ALP protein expression was determined using ALP staining. As shown in Fig. 2A (upper panel), cells treated with BBR during the differentiation process exhibited increased staining compared with that in the control cells, in a dose-dependent manner. Furthermore, staining of cells treated with LPS was markedly decreased compared with that in the control cells. Notably, BBR reversed the LPS-induced reduction (Fig. 2A; lower panel). In addition, intracellular Alp mRNA expression level exhibited a similar result (Fig. 2B). Compared with Alp mRNA expression in the control cells, there was a 13.7-fold increase induced by BBR treatment and an 8.1-fold change induced by BBR and LPS co-incubation. The gene expression level of Runx2, the key transcriptional factor during osteogenesis (25), was higher in cells treated with BBR and lower in LPS-treated cells. Furthermore, co-incubation with BBR and LPS reversed the LPS-mediated reduction of Runx 2 mRNA expression level (Fig. 2C). Similar results were also found for Ocn mRNA expression levels (Fig. 2D), which is one of the essential osteogenic marker genes (26). The regulation of BBR on SPP1 mRNA expression was similar with that on Ocn mRNA expression; however, the result was not significantly different (Fig. 2E). These findings indicated that BBR could accelerate osteogenic differentiation and assist with restricting LPS-induced adverse effects in BMSCs. expression were weak in undifferentiated BMSCs; however, it was hypothesized that BBR could serve a role in the adipogenic process. The maturity of adipose-like cells, which were treated with different concentrations of BBR in combination with or without LPS during the differentiated process, was investigated. As illustrated in the oil red $\mathrm{O}$ staining images, cells treated with a higher BBR dose exhibited fewer positive stained cells (Fig. 3A; upper panel). LPS increased the number of mature cells further, while BBR co-treatment reversed the effect in a dose-dependent manner (Fig. 3A; lower panel). It was found that BMSCs administrated with BBR combined with LPS had more positive cells compared with those treated with BBR alone. This suggested that BBR partly blocked differentiation.

The gene expression levels in differentiated BMSCs were also detected. As presented in Fig. 3B-D, the mRNA expression levels of all of the three adipogenic genes were decreased by BBR and increased by LPS. Furthermore, BBR combined with LPS decreased the LPS-stimulated Fabp4, Adipsin and Ppar $\gamma$ gene expression levels to a lower level in a dose-dependent manner. Taken together, it was found that BBR inhibited BMSCs adipogenesis and partly prevented the LPS-mediated effect.

BBR ameliorates LPS-stimulated $N F-\kappa B$ signaling activation and enhancement of pro-inflammatory factor expression. As LPS activates cells and the expression of the pro-inflammatory 
A

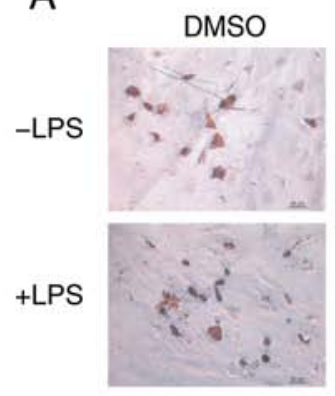

Fabp4

B

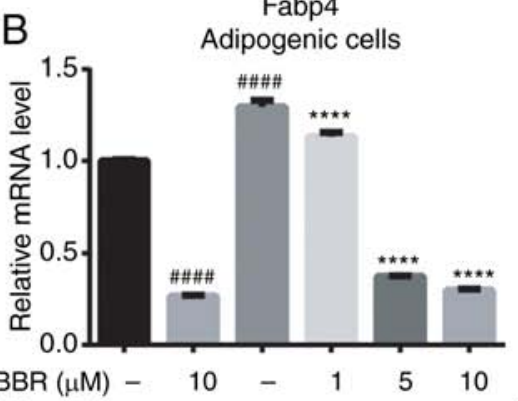

Adipogenic cells
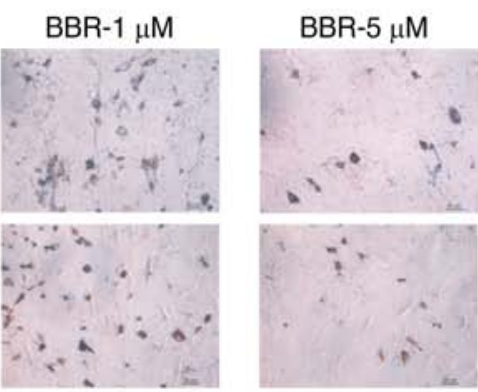

Adipsin

C

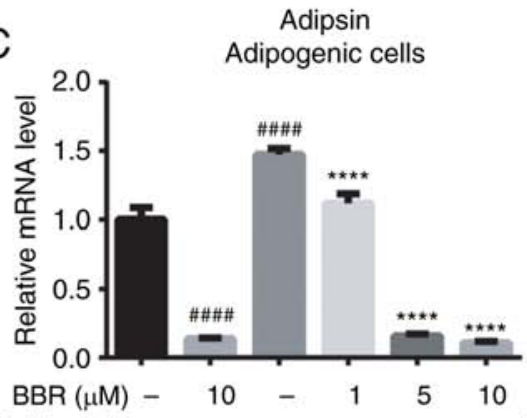

BBR-10 $\mu \mathrm{M}$

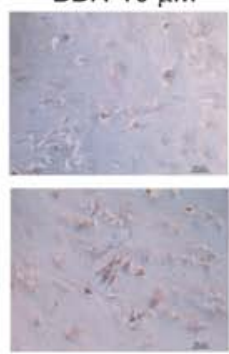

D

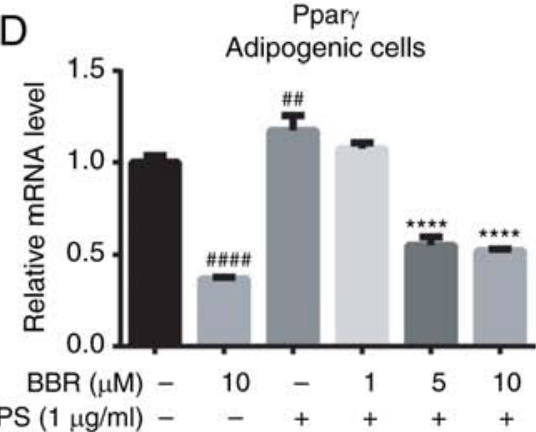

Figure 3. BBR inhibits adipogenesis in bone marrow-derived mesenchymal stem cells. The cells were incubated with BBR $(0,1,5$ or $10 \mu \mathrm{M})$ alone or simultaneously with LPS $(1 \mu \mathrm{g} / \mathrm{ml})$ in adipogenic media for 12 days. Then, the cells were detected using oil red $\mathrm{O}$ stain and reverse transcription-quantitative PCR analysis. (A) Images of the ALP stained cells were obtained using a microscope, at x 200 magnification. The mRNA expression levels of the (B) Fabp4, (C) Adipsin and (D) Ppar $\gamma$ adipogenic genes were measured. Their relative changes were normalized to the GAPDH expression levels. The data are presented as the mean \pm standard deviation of three independent experiments. ${ }^{\# \#} \mathrm{P}<0.01,{ }^{\# \# \# *} \mathrm{P}<0.0001$ vs. control group; ${ }^{* * * *} \mathrm{P}<0.0001$ vs. LPS group. BBR, berberine hydrochloride; LPS, lipopolysaccharide; Fabp4, fatty acid binding protein 4; Ppar $\gamma$, peroxisome proliferator-activated receptor $\gamma$; ALP, alkaline phosphatase.
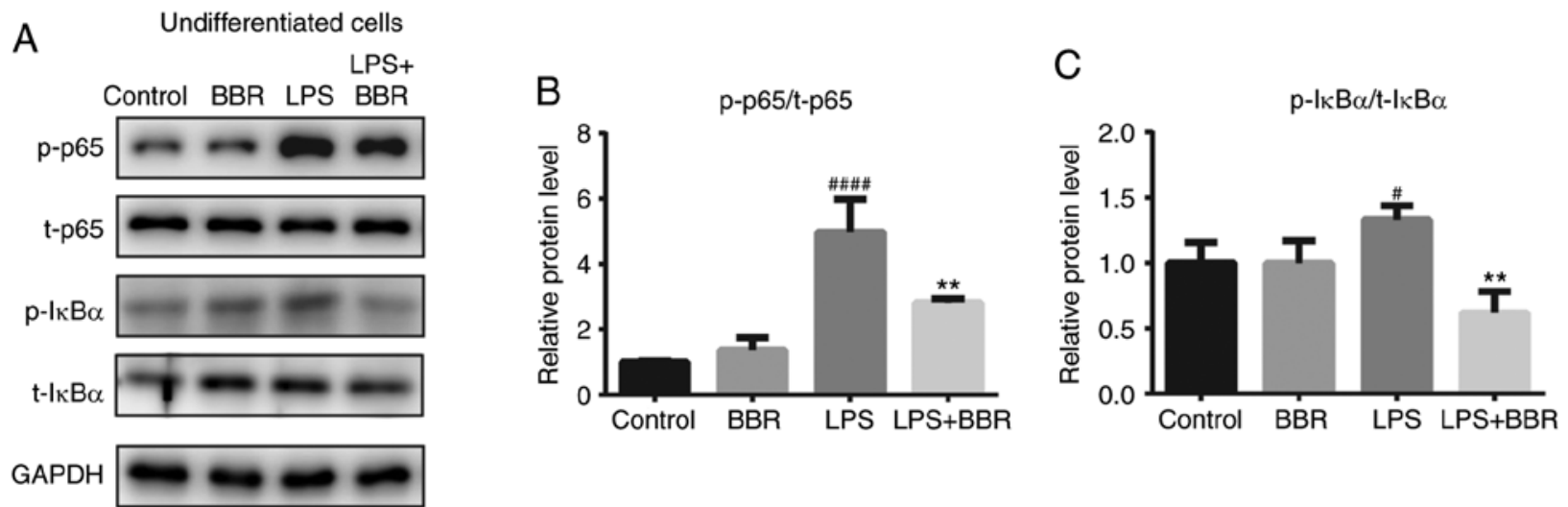

Figure 4. BBR protects bone marrow-derived mesenchymal stem cells from LPS-induced NF- $\mathrm{KB}$ activation under undifferentiated condition. Cells were incubated with DMSO (as the control), BBR $(10 \mu \mathrm{M})$, LPS $(1 \mu \mathrm{g} / \mathrm{ml})$ or both BBR and LPS for $2 \mathrm{~h}$. Then, the cells were harvested for western blot analysis (A) Bands of the p-and t- (B) NF-кB p65 subunit, (C) IкB $\alpha$ and GAPDH protein expression levels are shown and the results were semi-quantified. The data are presented as the mean \pm standard deviation of three independent experiments. ${ }^{*} \mathrm{P}<0.05,{ }^{\# \# \# "} \mathrm{P}<0.0001$ vs. control group; ${ }^{* *} \mathrm{P}<0.01$ vs. LPS group. T, total, $p$, phosphorylated; BBR, berberine hydrochloride; LPS, lipopolysaccharide; p-, phosphorylated; t-, total.

cytokines via the TLR4-NF- $\mathrm{B}$ signaling pathway, the effects of $\mathrm{BBR}$ on the primary proteins of the NF- $\mathrm{KB}$ signaling pathway were investigated. It is known that $p-\mathrm{I} \kappa \mathrm{B} \alpha$ and p-NF- $\kappa B$ p65 subunits are markers of TLR4/NF- $\kappa B$ pathway activation (27). BMSCs were cultured and treated with BBR and LPS, alone or in combination, for another $2 \mathrm{~h}$. It was found that the LPS-treated group exhibited darker p-p65 and p-IкB $\alpha$ bands compared with those in the control group and in the BBR-treated group (Fig. 4A). There was no effect from BBR alone; however, BBR decreased the LPS-stimulated activated protein expression levels. Densitometry analysis of the bands is shown in Fig. 4B and C. Notably, LPS treatment significantly increased the phosphorylation of the NF- $\kappa \mathrm{B}$ p65 subunit and I $\mathrm{B} \alpha$, and these increments were reversed when exposed to BBR simultaneously.

Subsequently, the product of the activated NF- $\kappa$ B signaling pathway was investigated using RT-qPCR, including the mRNA expression levels of TNF- $\alpha$, MCP-1, Il- 6 and Il-1 $\beta$. BMSCs were differentiated and treated as aforementioned, then mature osteoblast cells and adipose-like cells were harvested 


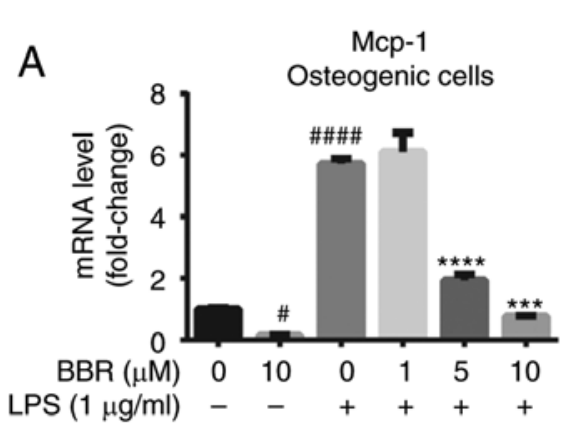

B

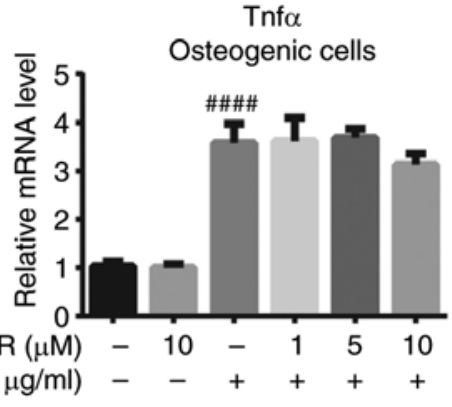

C

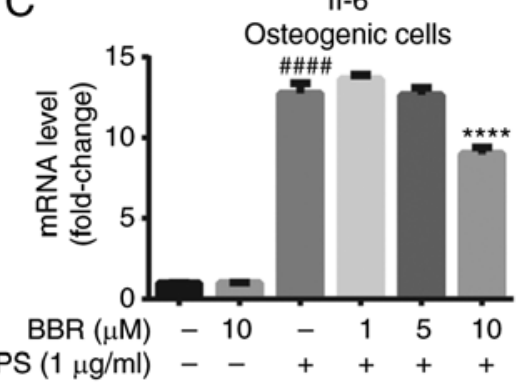

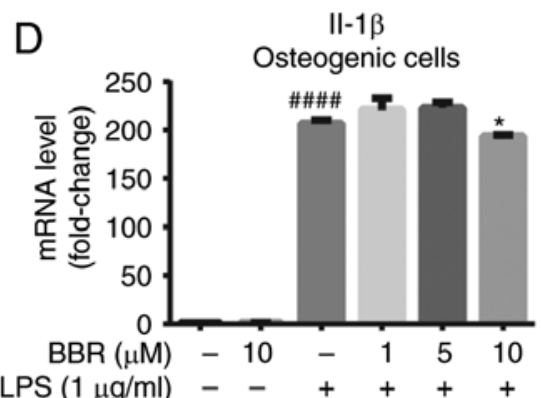

E

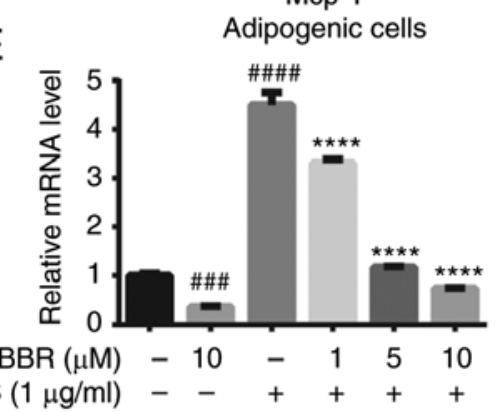

$\mathrm{F}$

$\operatorname{Tnf} \alpha$

Adipogenic cells

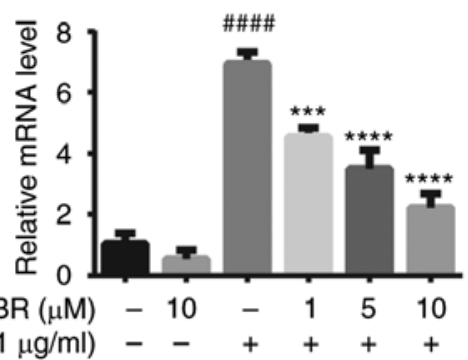

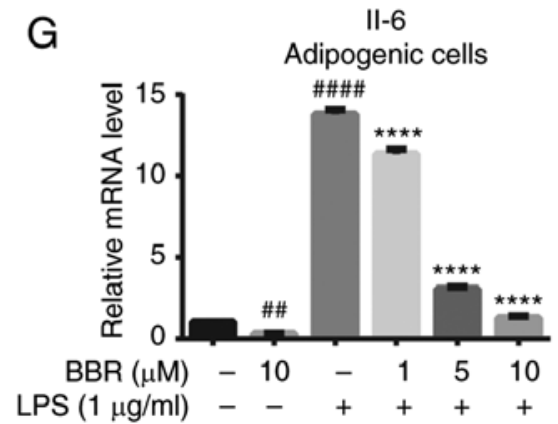

$\mathrm{H}$

II-1 $\beta$

Adipogenic cells

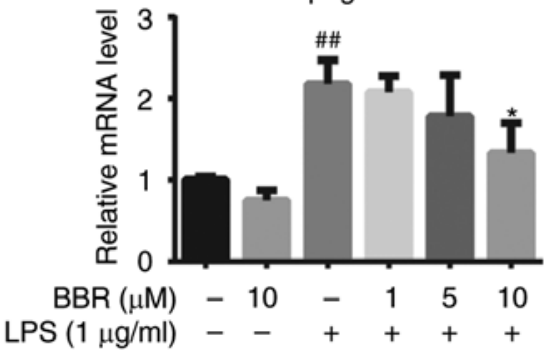

Figure 5. BBR alleviates LPS-induced inflammatory factor expression in both osteogenic and adipogenic differentiated bone marrow-derived mesenchymal stem cells. The cells were incubated with BBR $(0,1,5$ or $10 \mu \mathrm{M})$ or simultaneously with LPS $(1 \mu \mathrm{g} / \mathrm{ml})$ in osteogenic media for 7 days or in adipogenic media for 12 days. Then, the cells were harvested for reverse transcription-quantitative PCR analysis. The mRNA expression levels of the pro-inflammatory factors (A) MCP-1, (B) TNF- $\alpha$, (C) Il-6 and (D) Il-1 $\beta$ were measured in differentiated osteoblastic cells. (E) MCP-1, (F) TNF- $\alpha$, (G) Il- 6 and (H) Il-1 $\beta$ expression levels were also measured in adipogenic differentiated cells. Their relative changes were normalized to GAPDH levels. The data are presented as the mean \pm standard

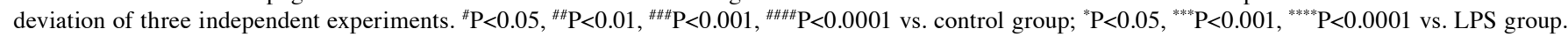
BBR, berberine hydrochloride; LPS, lipopolysaccharide; MCP-1, monocyte chemoattractant protein-1.

and detected. In osteogenic BMSCs (Fig. 5A-D), BBR alone had little effect on the pro-inflammatory factors except MCP-1; however, LPS significantly increased TNF- $\alpha$, MCP-1, Il-6 and Il-1 $\beta$ gene expression to a great extent. Moreover, the reversal effect of BBR against LPS was not strong. However, a dose-dependent change was still found, particularly on MCP-1 mRNA expression levels.

The regulation of BBR was notable in adipogenic BMSCs. The gene expression levels of MCP-1, Il-6 and Il-1 $\beta$ were alleviated with BBR treatment. LPS stimulated a 4.5-, 6.9-, 13.7- and 2.1-fold increase in the MCP-1, TNF- $\alpha$, Il- 6 and Il-1 $\beta$ mRNA expression levels, respectively. Furthermore, BBR co-treatment caused a significant and dose-dependent decrease in these expression levels (Fig. 5E-H). At $10 \mu \mathrm{M}$ concentration, BBR almost reversed the mRNA expression levels of MCP-1 and Il- 6 back to the basic level.

All the aforementioned results suggested that BBR efficiently decreased the mRNA expression levels of pro-inflammatory factors in both types of cells and may act more sensitively in adipogenic cells.

$B B R$ regulates the balance of osteogenic/adipogenic differentiation partly via AMP-activated protein kinase (AMPK) activation. As BBR typically acts as an adenosine AMPK agonist (28), it was hypothesized whether its regulation of osteogenesis/adipogenesis balance was due to AMPK activation. The efficiency of BMSC osteogenic and adipogenic differentiation with respective compound treatments was subsequently investigated.

For osteogenic differentiation, compared with that in the control cells, cells incubated with BBR stained darker, while compound C (AMPK antagonist)-treated cells stained lighter (Fig. 6A and B). The color of the stain in BBR and compound $\mathrm{C}$ co-incubated cells was darker compared with that in compound $\mathrm{C}$ only treated cells, and lighter compared with that in cells treated with BBR only treated cells 
A
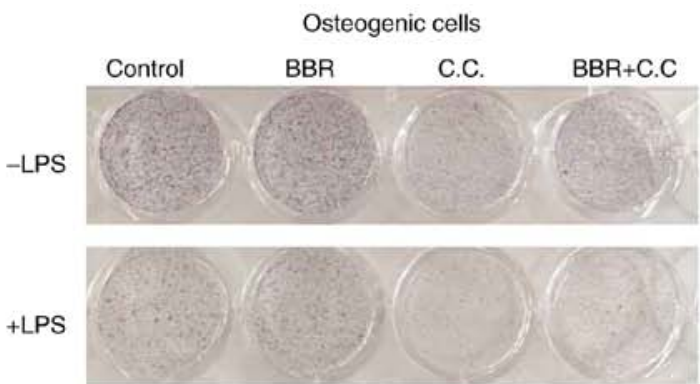

C Osteogenic cells

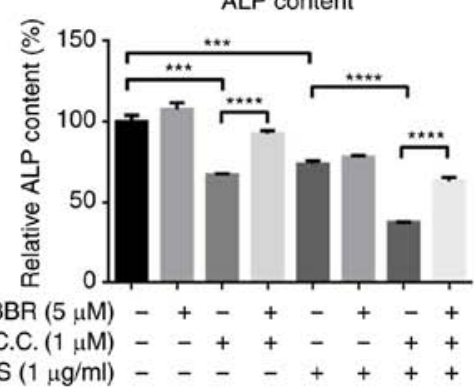

B

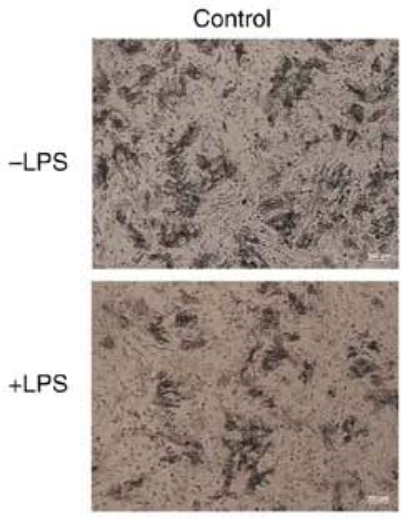

BBR
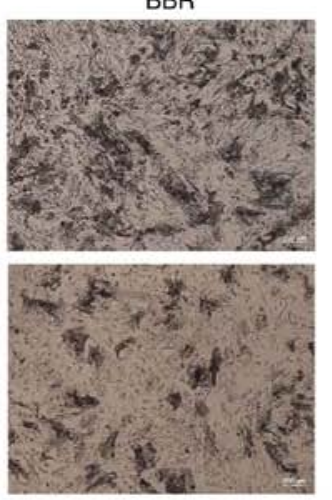

C.C.
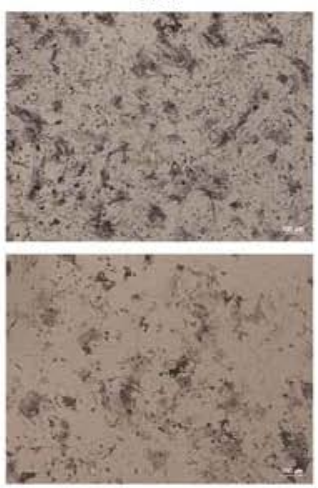

Adipogenic cells

D BBR C.C. BBR+C.C

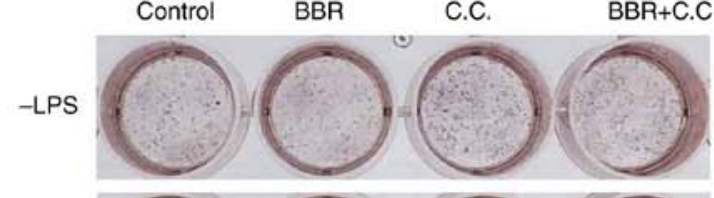

+ LPS
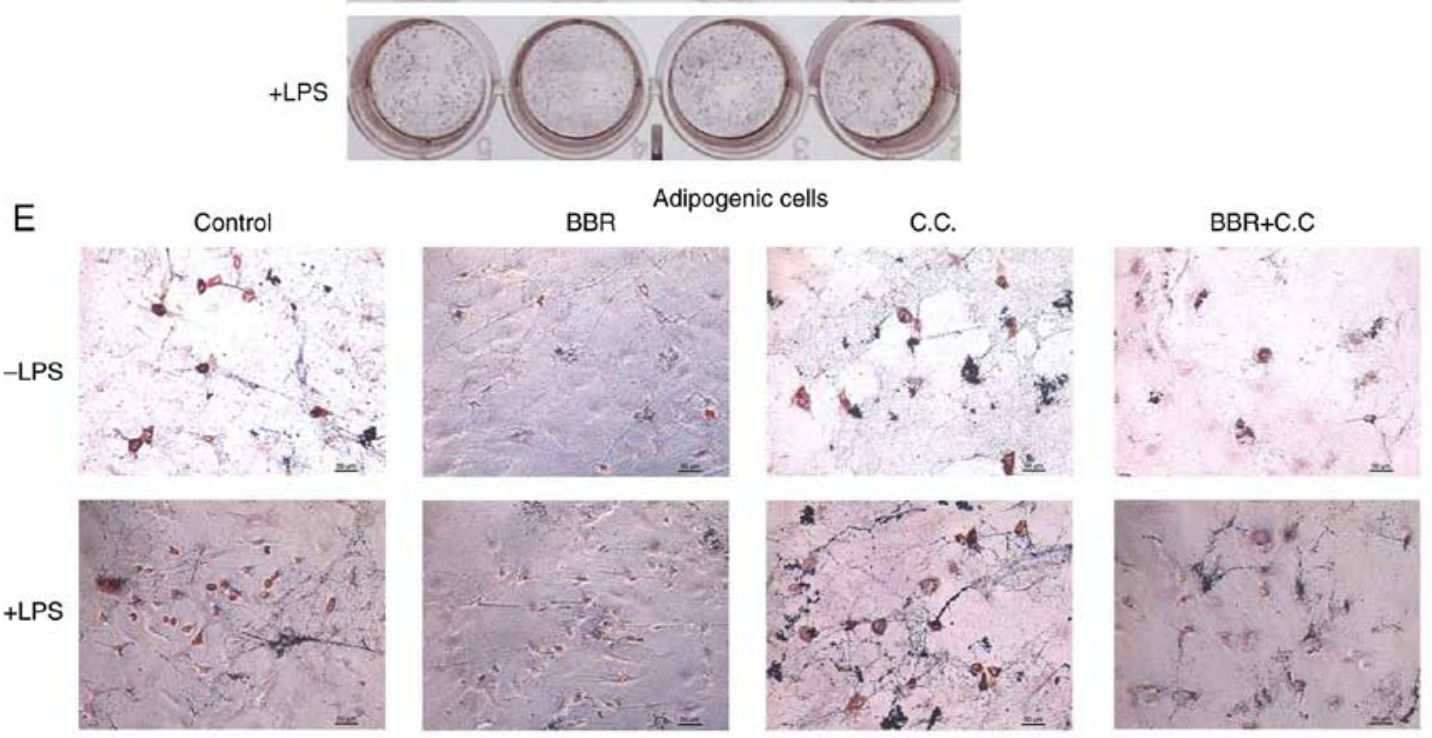

Figure 6. BBR regulates osteogenic and adipogenic differentiation via AMPK activation. The cells were incubated with BBR $(10 \mu \mathrm{M})$, C.C $(1 \mu \mathrm{M})$ or both, in the presence or absence of LPS $(1 \mu \mathrm{g} / \mathrm{ml})$, in osteogenic media for 7 days or in adipogenic media for 12days. Then, the cells were collected for ALP staining, ALP content assay or oil red O staining. The images of the ALP stained cells were obtained using a (A) camera and (B) microscope at x200 magnification (C) Relative ALP content levels of osteogenic cells were measured and normalized to control levels. The images of the oil red O stained cells were obtained using a (D) camera and (E) microscope at $\mathrm{x} 200$ magnification. The data are presented as the mean \pm standard deviation of three independent experiments. ${ }^{* * *} \mathrm{P}<0.001,{ }^{* * * *} \mathrm{P}<0.0001$. C.C, compound C; BBR, berberine hydrochloride; LPS, lipopolysaccharide; ALP, alkaline phosphatase.

(Fig. 6A and B; upper panel). Similar results were detected under the LPS-mediated inflammatory condition (Fig. 6A and B; lower panel). In addition, the intracellular ALP content was measured and the results are presented in Fig. 6C. The ALP content was weakly increased in the BBR group, while cells treated with compound C and LPS had decreased ALP content. Compared with that in the compound $\mathrm{C}$ group, the content of $\mathrm{ALP}$ in the BBR + compound $\mathrm{C}$ group was significantly higher, 
suggesting the recovery of ALP expression. Under inflammatory conditions, the LPS + compound C group showed a lower ALP level compared with that in the LPS, and LPS + BBR + compound $\mathrm{C}$ groups. Both the ALP staining and intracellular content demonstrated that altered AMPK activation affected osteogenic differentiation, and BBR could block the effect of compound $\mathrm{C}$.

For adipogenic differentiation, the number of positive cells in the BBR group was reduced compared with that in the control group, while the compound $\mathrm{C}$ group had more positive cells compared with that in the control group (Fig. 6D and E). The BBR + compound $\mathrm{C}$ group had a higher number of positive cells compared with that in the control group, but fewer compared with that in the compound $\mathrm{C}$ group. On the other hand, compared with that in the control group, LPS increased the number of positive cells, and the combination group with compound $\mathrm{C}$ had even higher numbers (Fig. 6D and $\mathrm{E}$ ). The LPS + BBR + compound C group had less stained cells compared with that in the LPS + compound C group. It was suggested that BBR reversed the pro-adipogenic differentiation of LPS, and compound C disturbed the anti-adipogenic function of BBR.

\section{Discussion}

Similar to periodontitis of teeth, peri-implantitis of implanted teeth can occur. Inflammatory responses caused by bacteria have been found to stimulate pro-inflammatory factor upregulation and contribute to the pathogenesis of both periodontitis and peri-implantitis (29). Therefore, controlling the inflammatory reaction is an active strategy to solve the peri-implant problem, by either reducing bacteria growth or alleviating the accumulation of pro-inflammatory cytokines. Notably, it would be beneficial to have both options. Previous studies have reported that BBR was a broad-spectrum antibacterial agent (30), and also exhibited anti-inflammatory properties (28), thus, presenting as a suitable candidate for peri-implantitis therapy. Although BBR decreased the LPS-mediated inflammatory response in several types of cells $(28,31,32)$, the anti-inflammatory effect of BBR in BMSCs is yet to be fully elucidated. The present study demonstrated that BBR not only attenuated the LPS-induced NF- $\mathrm{BB}$ p65 and $\mathrm{I} \kappa \mathrm{B} \alpha$ activation in undifferentiated BMSCs, but also downregulated the pro-inflammatory factor expression levels in differentiated cells. These results were consistent with the expected effect, confirming BBR as a suitable candidate.

Besides anti-inflammation, bone regeneration is an important aspect for peri-implantitis therapy. Thus, it should be investigated whether a candidate would improve bone regeneration. Firstly, previous studies have reported the proosteogenesis effect of BBR $(20,33)$; however, it was not clear whether the action was sufficient to resist the effect by LPS. Secondly, LPS could cause the imbalance of chondrogenesis and adipogenesis in multi-potential BMSCs (18). The function of LPS in regulating osteogenesis and adipogenesis balance requires further investigation. In the present study, there was no significant cytotoxic effect of LPS at $1 \mu \mathrm{g} / \mathrm{ml}$ concentration but weak cytotoxicity was induced at the dose of $10 \mu \mathrm{g} / \mathrm{ml}$. Notably, the properties of LPS may vary at different concentrations. For instance, LPS promoted adipogenesis at a dose of $10 \mu \mathrm{g} / \mathrm{ml}$, but attenuated adipogenic differentiation at a concentration of $100 \mathrm{ng} / \mathrm{ml}(18,34)$. Thus, in the current study, in order to avoid the effect of cytotoxicity caused by high concentration of LPS on cell differentiation, the dose of $1 \mu \mathrm{g} / \mathrm{ml}$ was selected for subsequent experimentation. In a LPS-mediated inflammatory condition, the regulation of $\mathrm{BBR}$ on the complex roles of LPS-induced differentiation promotion or attenuation should also be investigated.

To answer these questions, the changes in undifferentiated and differentiated cells treated with BBR alone or in combination with LPS were investigated. Understanding the basic effect of BBR in undifferentiated cells may assist with predicting osteogenic or adipogenic differentiation tendency in the complex differentiated environment. In the present study, it was found that BBR reversed the LPS-induced low mRNA expression levels of osteogenic genes to a higher level (compared with that in the control group) in undifferentiated cells; however, the changes in the differentiated osteoblast were not as effective. Up to a $10 \mu \mathrm{M}$ concentration, BBR was not able to completely neutralize the inhibition of LPS. Furthermore, the changes in the ALP protein staining were moderate compared with that observed for the mRNA expression level. Analogously, the resistant role of BBR against LPS in regulating adipogenic gene expression level was weak in the undifferentiated BMSCs; however, it was stronger in the mature adipose-like cells. The oil red $\mathrm{O}$ stain assay further identified the high efficiency of BBR. The extent of the variation maybe different; however, the tendency of pro-osteogenic and anti-adipogenic effects of BBR were found to be similar, regardless of whether the BMSCs were differentiated or not. In other words, LPS-mediated osteogenic and adipogenic differentiation was rectified by BBR.

Given that BBR is an activator of AMPK, it was hypothesized that BBR could modulate the balance of osteogenic and adipogenic differentiation by activating AMPK. Therefore, an AMPK inhibitor, compound $\mathrm{C}$, was used. The present results identified that compound $\mathrm{C}$ attenuated the effects of BBR; however, its strong regulation of anti-osteogenesis and pro-adipogenesis was notable. It was suggested that up- and down-regulation of AMPK could enhance the pro-osteogenic and pro-adipogenic effects, accordingly. BBR has been revealed to competitively bind with myeloid differentiation protein (MD-2) and interfere with the binding of the TLR4/ MD-2 complex with LPS $(35,36)$; thus, BBR acts as a highaffinity LPS antagonist. However, these molecular docking data were the result of computer simulation, and not from experimental detection. In the present study, BBR reversed the effects of LPS; however, this does not suggest a direct interaction between BBR and LPS. Until now, the mechanism of action was unknown, regarding whether it was direct, indirect or mixed. Based on the aforementioned results, further investigation is required to elucidate the direct competitive antagonism. Elimination of LPS function by knockout or mutation of the MD-2 gene may assist with identification or exclusion of the direct method. Until this is identified, it can only be hypothesized that BBR attenuated the LPS-mediated effects, at least partly, via the activation of AMPK. Furthermore, BBR is a multi-target molecule. For instance, ubiquitin-like with PHD and RING Finger domains 1 is also a BBR target protein (37), which could negatively regulate Ppar $\gamma$ in colorectal cancer (38). 
Whether the ubiquitin-dependent proteasome system serves a role in the osteogenic differentiated regulation in BMSCs also requires confirmation.

In the present study, there was an interesting finding that LPS stimuli decreased Ppar $\gamma$ mRNA expression level in undifferentiated BMSCs but increased its gene expression level in the adipogenic cells. Simonin et al (39) reported a decrease in Ppar $\gamma$ expression induced by $10 \mu \mathrm{g} / \mathrm{ml}$ LPS in rat synovial fibroblasts. Moreover, LPS $(0.5 \mu \mathrm{g} / \mathrm{ml})$ was found to downregulate Ppar $\gamma$ mRNA and protein expression levels in vascular smooth muscle cells (40). The effects of LPS on Ppar $\gamma$ gene expression in these cells were consistent with the current findings in the undifferentiated BMSCs. On the other hand, similar to the present results, another research team reported that LPS increased Ppar $\gamma$ mRNA expression under the adipogenic condition (13). Sun et al (41) revealed that mineralization of ST2 cells is inhibited by PPAR $\gamma$ agonist troglitazone, while osteogenic differentiation of BMSCs from osteoblast-targeted PPAR $\gamma$ knock-out mice increases compared with wild type mice. Cortical bone formation in the knock-out mice is also increased. In fact, Ppar $\gamma$ is a protein with complex mechanism, which could inhibit certain gene expression levels in untreated cells and enhance these in LPS-stimulated cells (42). Thus, it was suggested that the inhibition of Ppar $\gamma$ gene expression by LPS in undifferentiated BMSCs may reflect a potential osteogenic role. However, under adipogenic conditions, Ppar $\gamma$ expression and activation was increased, and LPS further promoted Ppar $\gamma$ expression via other mechanisms. This mechanism requires further study.

In summary, the present study demonstrated that BBR ameliorated the LPS-induced imbalance of osteogenic and adipogenic differentiation in BMSCs and promoted osteogenesis. The current study provided a potential drug candidate, $\mathrm{BBR}$, to solve the peri-implantitis problem, with regards to its multiple role in anti-bacterial capacity (43), anti-inflammation action and osteogenesis.

\section{Acknowledgements}

Not applicable.

\section{Funding}

This work was supported by the Natural Science Foundation of Shanghai (grant no. 19ZR1439600) and the Natural Science Talent Cultivation Foundation of Shanghai Tenth People's Hospital (grant no. 040318055).

\section{Availability of data and materials}

The datasets used and analyzed during the current study are available from the corresponding author on reasonable request.

\section{Authors' contributions}

YX, SQ, RZ and FC designed the research. RZ and HL carried out the PCR analysis. FC and XZ performed the cell differentiation and staining. XW isolated the primary cells. FY and GS supervised the project and contributed to data analysis. YX, SQ and RZ contributed to the writing of the manuscript.
$\mathrm{XZ}$ and $\mathrm{XW}$ helped with manuscript revision and SQ and YX confirmed the authenticity of the data. All authors read and approved the final manuscript.

\section{Ethics approval and consent to participate}

All animal procedures performed in this work were approved by the Animal Ethics Committee of Shanghai Tenth People's Hospital, Shanghai, China (approval no. 2018-4487).

\section{Patient consent for publication}

Not applicable.

\section{Competing interests}

The authors declare that they have no competing interests.

\section{References}

1. Dreyer H, Grischke J, Tiede C, Eberhard J, Schweitzer A, Toikkanen SE, Glöckner S, Krause G and Stiesch M: Epidemiology and risk factors of peri-implantitis: A systematic review. J Periodontal Res 53: 657-681, 2018.

2. Heitz-Mayfield LJ: Diagnosis and management of peri-implant diseases. Aust Dent J 53 (Suppl 1): S43-S48, 2008

3. Daubert DM, Weinstein BF, Bordin S, Leroux BG and Flemming TF: Prevalence and predictive factors for periimplant disease and implant failure: A cross-sectional analysis. J Periodontol 86: 337-347, 2015.

4. Mishler OP and Shiau HJ: Management of peri-implant disease: A current appraisal. J Evid Based Dent Pract 14 (Suppl): 53-59, 2014.

5. Salvi GE, Cosgarea R and Sculean A: Prevalence and mechanisms of peri-implant diseases. J Dent Res 96: 31-37, 2017.

6. Derks J and Tomasi C: Peri-implant health and disease. A systematic review of current epidemiology. J Clin Periodontol 42 (Suppl 16): S158-S171, 2015.

7. Figuero E, Graziani F,Sanz I,Herrera D and Sanz M: Management of peri-implant mucositis and peri-implantitis. Periodontol 2000 66: 255-273, 2014.

8. Hentenaar DFM, De Waal YCM, Van Winkelhoff AJ, Meijer HJA and Raghoebar GM: Non-surgical peri-implantitis treatment using a pocket irrigator device; clinical, microbiological, radiographical and patient-centred outcomes-A pilot study. Int J Dent Hyg 18: 403-412, 2020.

9. Takeuchi O, Hoshino K, Kawai T, Sanjo H, Takada H, Ogawa T, Takeda K and Akira S: Differential roles of TLR2 and TLR4 in recognition of gram-negative and gram-positive bacterial cell wall components. Immunity 11: 443-451, 1999.

10. Cui L, Feng L, Zhang ZH and Jia XB: The anti-inflammation effect of baicalin on experimental colitis through inhibiting TLR4/NF- $\kappa$ B pathway activation. Int Immunopharmacol 23: 294-303, 2014

11. Park H, Noh AL, Kang JH, Sim JS, Lee DS and Yim M: Peroxiredoxin II negatively regulates lipopolysaccharideinduced osteoclast formation and bone loss via JNK and STAT3. Antioxid Redox Signal 22: 63-77, 2015.

12. Sul OJ, Park HJ, Son HJ and Choi HS: Lipopolysaccharide (LPS)-induced autophagy is responsible for enhanced osteoclastogenesis. Mol Cells 40: 880-887, 2017.

13. Bonsignore LA, Anderson JR, Lee Z, Goldberg VM and Greenfield EM: Adherent lipopolysaccharide inhibits the osseointegration of orthopedic implants by impairing osteoblast differentiation. Bone 52: 93-101, 2013.

14. Nouneh RA, Wataha JC, Hanes PJ and Lockwood PE: Effect of lipopolysaccharide contamination on the attachment of osteoblast-like cells to titanium and titanium alloy in vitro. J Oral Implantol 27: 174-179, 2001.

15. Insua A, Monje A, Wang HL and Miron RJ: Basis of bone metabolism around dental implants during osseointegration and peri-implant bone loss. J Biomed Mater Res A 105: 2075-2089, 2017. 
16. Chen Q, Shou P, Zheng C, Jiang M, Cao G, Yang Q, Cao J, Xie N, Velletri T, Zhang X, et al: Fate decision of mesenchymal stem cells: Adipocytes or osteoblasts? Cell Death Differ 23: $1128-1139,2016$

17. Chen KY, Chung CM, Chen YS, Bau DT and Yao CH: Rat bone marrow stromal cells-seeded porous gelatin/tricalcium phosphate/oligomeric proanthocyanidins composite scaffold for bone repair. J Tissue Eng Regen Med 7: 708-719, 2013.

18. Zhu J, Tang H, Zhang Z, Zhang Y, Qiu C, Zhang L, Huang P and Li F: Kaempferol slows intervertebral disc degeneration by modifying LPS-induced osteogenesis/adipogenesis imbalance and inflammation response in BMSCs. Int Immunopharmacol 43: 236-242, 2017.

19. Pirillo A and Catapano AL: Berberine, a plant alkaloid with lipid- and glucose-lowering properties: From in vitro evidence to clinical studies. Atherosclerosis 243: 449-461, 2015.

20. Lee HW, Suh JH, Kim HN, Kim AY, Park SY, Shin CS, Choi JY and Kim JB: Berberine promotes osteoblast differentiation by Runx 2 activation with p38 MAPK. J Bone Miner Res 23: 1227-1237, 2008

21. Han SY and Kim YK: Berberine Suppresses RANKL-induced osteoclast differentiation by inhibiting c-Fos and NFATc1 expression. Am J Chin Med 47: 439-455, 2019.

22. Hu JP, Nishishita K, Sakai E, Yoshida H, Kato Y, Tsukuba T and Okamoto K: Berberine inhibits RANKL-induced osteoclast formation and survival through suppressing the NF-kappaB and Akt pathways. Eur J Pharmacol 580: 70-79, 2008.

23. Livak KJ and Schmittgen TD: Analysis of relative gene expression data using real-time quantitative PCR and the 2(-Delta Delta C(T)) Method. Methods 25: 402-408, 2001.

24. Shanbhag S, Mohamed-Ahmed S, Lunde THF, Suliman S, Bolstad AI, Hervig T and Mustafa K: Influence of platelet storage time on human platelet lysates and platelet lysate-expanded mesenchymal stromal cells for bone tissue engineering. Stem Cell Res Ther 11: 351, 2020.

25. Huang Y, Hou Q, Su H, Chen D, Luo Y and Jiang T: miR-488 negatively regulates osteogenic differentiation of bone marrow mesenchymal stem cells induced by psoralen by targeting Runx 2 . Mol Med Rep 20: 3746-3754, 2019.

26. Lee YC, Chan YH, Hsieh SC, Lew WZ and Feng SW: Comparing the osteogenic potentials and bone regeneration capacities of bone marrow and dental pulp mesenchymal stem cells in a rabbit calvarial bone defect model. Int J Mol Sci 20: 5015, 2019.

27. Zhang J, Zheng Y, Luo Y, Du Y, Zhang X and Fu J: Curcumin inhibits LPS-induced neuroinflammation by promoting microglial M2 polarization via TREM2/ TLR4/ NF- $\kappa$ B pathways in BV2 cells. Mol Immunol 116: 29-37, 2019.

28. Zou K, Li Z, Zhang Y, Zhang HY, Li B, Zhu WL, Shi JY, Jia Q and Li YM: Advances in the study of berberine and its derivatives: A focus on anti-inflammatory and anti-tumor effects in the digestive system. Acta Pharmacol Sin 38: 157-167, 2017.

29. Yan Q, Li Y, Cheng N, Sun W and Shi B: Effect of retinoic acid on the function of lipopolysaccharide-stimulated bone marrow stromal cells grown on titanium surfaces. Inflamm Res 64: 63-70, 2015.

30. Stermitz FR, Lorenz P, Tawara JN, Zenewicz LA and Lewis K Synergy in a medicinal plant: Antimicrobial action of berberine potentiated by 5 -methoxyhydnocarpin, a multidrug pump inhibitor. Proc Natl Acad Sci USA 97: 1433-1437, 2000.
31. Zhang H, Shan Y, Wu Y, Xu C, Yu X, Zhao J, Yan J and Shang W: Berberine suppresses LPS-induced inflammation through modulating Sirt1/NF- $\kappa$ B signaling pathway in RAW264.7 cells. Int Immunopharmacol 52: 93-100, 2017.

32. Liang Y, Fan C, Yan X, Lu X, Jiang H, Di S, Ma Z, Feng Y, Zhang Z, Feng P, et al: Berberine ameliorates lipopolysaccharideinduced acute lung injury via the PERK-mediated Nrf2/HO-1 signaling axis. Phytother Res 33: 130-148, 2019.

33. Tao K, Xiao D, Weng J, Xiong A, Kang B and Zeng H: Berberine promotes bone marrow-derived mesenchymal stem cells osteogenic differentiation via canonical $\mathrm{Wnt} / \beta$-catenin signaling pathway. Toxicol Lett 240: 68-80, 2016.

34. Fiedler T, Salamon A, Adam S, Herzmann N, Taubenheim J and Peters K: Impact of bacteria and bacterial components on osteogenic and adipogenic differentiation of adipose-derived mesenchymal stem cells. Exp Cell Res 319: 2883-2892, 2013.

35. Chu M, Ding R, Chu ZY, Zhang MB, Liu XY, Xie SH, Zhai YJ and Wang YD: Role of berberine in anti-bacterial as a highaffinity LPS antagonist binding to TLR4/MD-2 receptor. BMC Complement Altern Med 14: 89, 2014.

36. Nagai Y, Akashi S, Nagafuku M, Ogata M, Iwakura Y, Akira S, Kitamura T, Kosugi A, Kimoto M and Miyake K: Essential role of MD-2 in LPS responsiveness and TLR4 distribution. Nat Immunol 3: 667-672, 2002

37. Gu C, Yin Z, Nie H, Liu Y, Yang J, Huang G, Shen J, Chen L and Fei J: Identification of berberine as a novel drug for the treatment of multiple myeloma via targeting UHRF1. BMC Biol 8: 33 , 2020.

38. Sabatino L, Fucci A, Pancione M, Carafa V, Nebbioso A, Pistore C, Babbio F, Votino C, Laudanna C, Ceccarelli M, et al: UHRF1 coordinates peroxisome proliferator activated receptor gamma (PPARG) epigenetic silencing and mediates colorectal cancer progression. Oncogene 31: 5061-5072, 2012.

39. Simonin MA, Bordji K, Boyault S, Bianchi A, Gouze E, Bécuwe P, Dauça M, Netter P and Terlain B: PPAR-gamma ligands modulate effects of LPS in stimulated rat synovial fibroblasts. Am J Physiol Cell Physiol 282: C125-C133, 2002.

40. Qu R-N and Qu W: Metformin inhibits LPS-induced inflammatory response in VSMCs by regulating TLR4 and PPAR- $\gamma$. Eur Rev Med Pharmacol Sci 23: 4988-4995, 2019.

41. Sun H, Kim JK, Mortensen R, Mutyaba LP, Hankenson KD and Krebsbach PH: Osteoblast-targeted suppression of PPAR $\gamma$ increases osteogenesis through activation of mTOR signaling. Stem Cells 31: 2183-2192, 2013.

42. Sergeeva MG, Aleshin SE, Grabeklis S and Reiser G: PPAR activation has dichotomous control on the expression levels of cytosolic and secretory phospholipase A2 in astrocytes; inhibition in naïve, untreated cells and enhancement in LPS-stimulated cells. J Neurochem 115: 399-410, 2010.

43. Huang X, Wang P, Li T, Tian X, Guo W, Xu B, Huang G, Cai D, Zhou F, Zhang H, et al: Self-assemblies based on traditional medicine berberine and cinnamic acid for adhesion-induced inhibition multidrug-resistant Staphylococcus aureus. ACS Appl Mater Interfaces 12: 227-237, 2020.

This work is licensed under a Creative Commons Attribution-NonCommercial-NoDerivatives 4.0 International (CC BY-NC-ND 4.0) License. 